stimulated to act in its characteristic manner. The contents of the small intestine are quickly moved along the coils, and in the large intestine the action is similar to that ascribed to senna. When calomel is given with a meal no increase of secretion appears to occur, the rapid transit alone sufficing to explain the semi-fluid consistence of the stools. If the calomel is given some hours after a meal, and thus acts in greater concentration, peristalsis is still more active, especially in the colon, and the stools are naturally more fluid. The total emptying of the bowel by calomel is very striking, and there would appear to be no better drug for this purpose were it not for the risk of absorption of the drug.

References.-Magnus, Pfliiger's Archiv., Bd. cxxii. Padtberg, Pflüger's Archiv., Bd. cxxix., Bd. cxxxiv. Stierlin, Münch. med. Wochenschr., 1910, No. 27. Meyer-Betz and Gebhardt, Münch med. Wochenschr., 1912, No. 33.

\title{
MENTAL DISEASES.
}

\author{
By JAMES MIDDLEMASS, M.D., F.R.C.P., \\ Medical Superintendent, Sunderland Borough Asylum.
}

\section{The Pathology of Senile Insanity.}

AN important and very interesting paper has recently been written by Marinesco on the results of his examination of the brain in senile insanity (L'Encéph., February 1912, p. 105). About 12 years ago Nissl expressed his belief that careful examination of the brain in cases of insanity would reveal a definite pathological change. He has himself done something to justify his belief, but it cannot be said that the goal, highly desirable though it is, has yet been reached. There have lately, however, been distinct steps towards reaching it, and in probably no other form of mental disease is this more true than in senile insanity. Research tends to show that this disease is not of one type only, but has several varieties, and that these are accompanied by different pathological alterations in the brain. Fischer named one variety presbyophrenia, and described a characteristic brain lesion. Alzheimer described another, associated with special changes in the nerve-cells of the cortex. Dupré and his pupils have drawn attention to the relations of presbyophrenia to Korsakoff's psychosis. Various other observers have recorded the results of careful examinations, and have apparently placed it beyond doubt that in many cases of senile insanity there is a characteristic cerebral lesion, which may now with considerable certainty be regarded as the pathological cause.

Marinesco first observed this lesion in 1892, and ever since he has been continuing his researches. The present paper is the outcome of 
his most recent work. In his first observations he described the occurrence of numerous small round nodules (plaques) in the grey matter in various layers, and regarded them as neuroglial sclerosis. In 1907 Fischer also described these nodules, and definitely stated that they were lesions characteristic of presbyophrenia. In addition to these nodules he observed peculiar changes in the nerve fibres. $\mathrm{He}$ regarded the nodules as areas of necrosis, which induce proliferative changes on the part of the surrounding neurofibrils. He failed to find them in other than senile cases, and also found that they were not present in all senile cases. He therefore concluded that they were characteristic of one variety only of senile insanity, and that consequently the latter consisted of more than one group. Bonfiglio regarded the nodules as a formation round a necrosed ganglionic cell. Hübner considered the nodules to arise in relation to the bloodvessels. Other observers have investigated the condition and recorded their views as to its cause.

In describing his latest researches Marinesco draws attention at the outset to the variety of histological methods used by previous workers, and states that some of the divergent views expressed may be so explained. He describes his own in detail, and claims that they permit of the recognition of the changes in their earliest stages, and do not dissolve out nor affect any of the pathological products. The tissues are fixed in formalin and impregnated with silver nitrate, which is afterwards reduced by pyrogallic acid. For the neuroglia the methods of Merzbacher and Bielschowsky were used. Various aniline dyes, safranine, thionine, etc., may be used as differential stains for special purposes.

The elinical history of one case investigated by the author is given in short form. The patient was a woman of 54, who three years before had a paralytic stroke. Mental disturbance supervened in the form of verbal amnesia, word-blindness, agraphia, apraxia, and certain symptoms of asymbolia. At the post-mortem examination there was found a softening of the left optic thalamus, and smaller ones in the corpus striatum. In addition there was observed in the cerebral cortex a large number of the nodules already referred to. They were most numerous in the right occipital region, less so in the cornu ammonis and hippocampal convolution, in the frontal and temporal convolutions. They were not at all numerous in the left hemisphere, and were absent in the left cornu ammonis. There was no difference in their distribution over the summits of the convolutions compared with the base of the furrows. As regards their distribution in the various cortical layers, the order of frequency was $3 \mathrm{rd}, 5 \mathrm{th}, 2 \mathrm{nd}, 1 \mathrm{st}$, and 6 th. They were absent from the white matter. Their size varied from $16 \mu$. by $14 \mu$. to $80 \mu$. by $72 \mu$. They were rounded, oval, or ovoid in shape, but sometimes they were irregular. The larger ones have a very complex 
structure, and require several methods to unravel. The modification of the Cajal method, which he adopted, was the most useful for studying the early formation of the nodules, and especially the fibrous elements. At first there are formed between the nerve-cells or close to them isolated rod-shaped bodies (bâttonets). These then join together and form star-shaped masses. They gradually increase in size by the deposition on them of more rods. The nodules form in the neighbourhood of a nerve-cell or vessel, or may enclose one or other of these, and they also contain a number of nerve-fibres, of neuroglia fibres, neuroglia cells, or macrophages. In the larger-sized nodules there are three zones, a central nucleus, an intermediate, and an outer layer. The latter cuts off the nodules from the surrounding healthy tissue. The degree to which these zones are developed varies much in individual nodules. The dimensions of the layers are given for thirty different nodules. The central zone or nucleus is rounded in form, and may be single or multiple. In many instances it shows a fine acicular deposit on its surface, giving it a rayed appearance. By some this deposit has been regarded as of crystalline nature, but Marinesco does not agree with this. Besides these spicules there are also to be seen filaments uniting the central and outer layers, giving in some instances a wheel-like appearance. The presence of these nodules induces remarkable changes in the surrounding nervous and neuroglia elements. The former show degeneration, regeneration, and metamorphosis, due probably both to mechanical and to chemical action. The phenomena of regeneration play a most important part in the production of the changes seen. New nerve-fibres form and surround or penetrate the nodule. The author regards these changes as exactly analogous to what occurs in nerve regeneration after section. Changes also occur in the neuroglia, but they are not very marked. The walls of the arterioles become thickened and the lumen diminished. Round them great numbers of spider-cells can be seen. The nerve-cells, apart from excessive pigmentation, do not show much change. In the case of another patient, a woman over 100 years old, Marinesco found some peculiar alterations in neurofibrils of the cells, which he describes in some detail, but this, apparently, is not a constant change.

Discussing the nature of these various morbid appearances, the author admits that it is impossible to explain them satisfactorily. He cannot say of what the central part of the nodules consists ; one can offer only conjectures. He does not think it is formed from either nerve or neuroglia cells. He considers that the substance which forms the rod-shaped bodies, the earliest stage in the formation of the nodules, is of colloidal nature, but different from that which forms amyloid bodies. It may be deposited as a result of disturbances of metabolism or disassimilation, it may belong to the class of mono-aminophosphatides or aminolipotides, but this is merely a speculation. 
This very interesting paper, indicative of prolonged and careful work, is illustrated by four plates containing 18 figures showing the various conditions described in the text.

\section{On Some Problems Presented by General Paralysis.}

Dr. Macfie Campbell, in an instructive short paper (Amer. Journ. of Ins., January 1912, p. 491), discusses some of the difficulties encountered in the correlation of focal symptoms of brain disease with the post-mortem findings in many cases of general paralysis. Everyone is familiar with cases of that disease who present symptoms which ordinarily would be taken as conclusive evidence of a local cerebral lesion. This is specially so with Jacksonian fits, localised paralyses, or anæsthesia and hemianopia. And yet when examined there may be no change to account for these very definite symptoms. Dr. Campbell records' some cases in which a local lesion was found, but points out that in some of these the local lesion is irrelevant to the general paralysis, while in others it is based on a process which has a common origin with general paralysis, e.g., endarteritis. He also records examples of cases by no means uncommon in which the diagnosis of general paralysis is possible only after microscopic examination of the brain, the usual naked-eye signs being absent. This is undoubtedly a matter of very great importance, and should always, if possible, be carried out in every doubtful case. Dr. Campbell further records some cases in which focal symptoms were present, which on microscopic examination revealed an unusual intensity of the disease process on that side of the brain in which the focus was diagnosed to be. He suggests the more careful examination microscopically of all such cases, and without doubt he is entirely right.

It is probably not too much to say that if the mental and physical symptoms in any individual case of general paralysis could be correlated to special pathological changes in particular regions of that person's brain, the problem of cerebral function would to a large extent be solved. This would certainly entail much careful and prolonged work, and possibly also the discovery of more refined histological and chemical methods, but it seems quite the most useful avenue to lead to this substantial advance in knowledge.

\section{Seruid Reaction in General Paralysis.}

Drs. Eyman and O'Brien are continuing the work begun by the latter in investigating the Bacillus paralyticans of Ford Robertson, and report the latest results of their work (Amer. Journ. of Ins., February 1912 , p. 485). They followed the lines of the Wassermann reaction, 
using as antigen the Bacillus paralyticans instead of the usual extract of syphilitic liver. By this method the results are somewhat similar to those found with Wassermann's reaction. With the blood of general paralytics the successful results came out as 90 per cent. In the wives of general paralytics 60 per cent. gave a positive reaction; prostitutes, 73 per cent. Their conclusion from these researches is that in this disease syphilis is not the only potent factor, but that there is also another special venereal infection distinct.from syphilis concerned in its production.

\section{Chemistry of Nervous and Mental Diseases.}

Though there is as yet little definite knowledge of the chemical processes accompanying, or it may be causing, nervous and mental disease, signs are not wanting that investigations are being pushed to attain more exact and extended information in this important subject. All chemical investigation, even of inorganic substances, consumes much time and involves great skill and labour, and when organic materials. are concerned, the time, skill, and labour are immensely greater. Dr. Barnes (Amer. Journ. of Ins., January 1912, p. 431) gives a summary of present knowledge of the subject, and a very full bibliography He has not much faith in many of the clinical investigations which have recently been published, as he considers they have been performed by persons unskilled in chemical methods, and conclusions have been drawn without knowledge of the pitfalls which lie ready to entrap those without the requisite experience. He discusses each of the bestknown forms of mental disease, and states what he considers the ascertained facts to be from the chemical point of view in the light of his. own experience and work. In dementia præcox there is evidence of the existence of an abnormality of metabolism, as shown by the departure from the normal in the amount of the neutral sulphur in the brain of such cases. The exact significance of this is, however, still uncertain. In manic-depressive insanity there are also evidences of some disturbance of metabolism. Several observers have recorded the presence of indicanuria, but whether this is a cause or a result of the brain disease is not yet clear. The connection between the two has still to be worked out.

In epilepsy many chemical investigations have been conducted. These show some metabolic disturbances, evidenced by alteration in the excretion of chlorides, uric acid, calcium, magnesium, and phosphorus. There is also an increase in the cholesterin in the cerebrospinal fluid. But the nature of these disturbances and their relation to the brain disease still awaits further investigation.

In general paralysis not one of the various agents suggested as causing the seizures can at present be held to do so. Further investi- 
gation has robbed each one in turn of its pride of place. Negative knowledge, though undoubtedly often useful, is by no means satisfying, and for that reason alone further work will presumably be forthcoming.

Speaking generally it cannot be said that as yet chemistry has added any striking new facts to our knowledge of mental disease. It has only given indications that such facts await discovery, and that the process of eliciting them will be one involving the expenditure of an unusual amount of time and care; and will be attained only by those possessing a complete chemical training.

\section{InJury and Nervous Disease.}

In view of the existence of the Workmen's Compensation Act the importance of reliable evidence as to the effect of injury in the production of mental disease is very apparent. Any reliable information on this subject is therefore very welcome. Dr. Warrington relates his experience, and also refers to the general literature of the subject in an important paper (Med. Chron., June 1911, p. 121). The only mental disease of which he writes is general paralysis. This, however, is the chief one in which the question of injury is likely to arise. Dr. Warrington quotes with approval Mott's opinion that it occurs only in the subjects of congenital or acquired syphilis. There is no doubt that the arguments in favour of this view become stronger with every advance in the knowledge of that disease. If such is a medical man's opinion the only question he has to answer in a compensation case is-Has the injury precipitated or accelerated the disease? Dr. Warrington concludes that to prove either of these it is necessary that the injury should be of considerable severity, causing distinct concussion or entailing prolonged confinement in bed. If the injury has been slight the mental shock must be severe, and shown by severe symptoms. The time interval between the injury and the first appearance of mental symptoms must not be too long-not over a year and a half. Post-traumatic dementia must be capable of being excluded. To facilitate this differential diagnosis the author gives the symptoms of general paralysis and of post-traumatic dementia as well as of cerebral syphilis, cerebral arterio-sclerosis, and alcoholic dementia, with which general paralysis may be confounded. It will thus be seen that this paper is most helpful and informing.

Gymnastics in the Treatuent of Psychomotor Instability.

Dr. Paul Boncour (Progrès Méd., 9th September 1911) advocates the use of rational gymnastic methods in the treatment of certain cases of mental defect in children in whom there are symptoms of motor restless- 
ness or lassitude. He is the head of a medico-pedagogic institute, and speaks from his own experience of the benefits of such methods. Their essential feature, if they are to be successful, is that they make a constant appeal to the various senses, and insensibly train the faculty of attention. All automatism is severely banned, because there is then no appeal to the attention, and even though great physical benefit may result, the mental faculties are in no way stimulated, and this is the main object desired. To attain this result the exercises must be interesting, they must not be unduly prolonged, they must be changed at given signals which vary for different movements, and they are best carried out to the accompaniment of music. Changes of rate and rhythm can in this way easily be effected. In his experience great benefit may be derived both in training the elementary mental faculties and in educating the muscles in the performance of co-ordinated movements. As in other forms of education, and to an even greater degree in this, each pupil must be studied individually, and the exercises modified to suit the individual requirements. The onset of fatigue must be carefully looked for, and if possible avoided. He gives an outline of a number of exercises which, with the necessary intervals for rest, require half an hour. This, he thinks, is as long as it is desirable to give at one lesson.

\section{The Asexualisation of the Unfit.}

As is well known, this subject has been publicly discussed in America to a much greater extent than has been the case here. Already four States-Indiana, California, Oregon, and Connecticut-have passed laws authorising such a procedure under due precautions. But for the action of the Governor of the State of Pennsylvania a similar law would now be in force there also. Dr. Barr, the chief physician of a State institution for mental defectives, pleads for the extension of such legislation, and gives his experience of the results of sterilisation in 200 cases (Alienist and Neurol., February 1912, p. 1). He states that in every case marked improvement has resulted. This is, to say the least of it, rather remarkable, and more details of cases would be desirable. In his paper he makes no reference to the possible abuses that might result were such a law to become general. It will be interesting to observe what happens in those American States where it is now in force after it has been in operation for some years longer. 